\title{
The impairment of verbal semantic memory: a single case study
}

\author{
AK COUGHLAN, ${ }^{*}$ ELIZABETH K WARRINGTON \\ From the National Hospital, Queen Square, London
}

SUMMARY We report our investigations of a single patient in whom there was a selective impairment of semantic memory. She had a marked deficit of individual word comprehension although other language and linguistic skills were relatively preserved. Here we document that her failures in word comprehension were stable over a long time period. She made "phonological" errors in defining meanings, which we argue are analogous to "visual" errors in reading. On verbal learning tasks her performance was shown to be relatively preserved, a finding which provides evidence of the dissociation of verbal semantic memory and episodic (event) memory.

The failure to comprehend the spoken word has long been recorded in the neurological literature and more recently quantitative investigations of such deficits have been reported. ${ }^{1-4}$ Warrington ${ }^{5}$ reported three patients with selective impairments of verbal comprehension which she identified as a deficit within the domain of semantic memory. These patients, with diffuse cerebral lesions, were shown to have an impoverished verbal comprehension vocabulary and their knowledge of word meanings was markedly degraded. Word frequency was a critical factor for all these patients, comprehension of high frequency words being relatively intact compared to that of less frequent words.

In this paper we present further data on one of these patients, EM. We have examined both the consistency of her failures in spoken word comprehension and the types of error she made and we have also investigated her performance on free recall verbal learning tasks. Our findings are relevant to consideration of both the nature of the semantic memory deficit and the relationship between semantic memory and verbal episodic (event) memory.

The degree of consistency in failures of spoken word comprehension has a bearing on the conceptualisation of the semantic memory deficit. In the context of written word comprehension deficits (the

*Present address and for reprint requests: Dr AK Coughlan, The Wolfson Medical Rehabilitation Centre, Atkinson Morley's Hospital, Copse Hill, London SW20 ONQ, UK.

Received 25 April 1981 and in revised form 19 September 1981

Accepted 26 September 1981 acquired dyslexias) it has been argued that consistent incorrect reading responses from session to session indicate degradation of the central representation of semantic information and that inconsistent incorrect responses indicate that the central representation may be intact but that access to it has become intermittent. ${ }^{7}$ Similar reasoning could be applied to spoken word comprehension deficits. Also, the analysis of reading errors has been crucial to the locus of written word comprehension deficits and likewise the analysis of spoken word comprehension errors is relevant to that of spoken word comprehension deficits. ${ }^{8}{ }^{9}$ However, no comparable analysis of spoken word comprehension deficits has as yet been reported.

As regards memory, Tulving ${ }^{10}$ has argued on theoretical grounds that a distinction should be drawn between semantic memory (memory for words, concepts, facts, etc) and episodic memory (memory for the occurrence of autobiographical events-one experimental analogue being verbal retention tasks). Neuropsychological data support this distinction; impairments of both semantic memory and episodic memory have been identified. ${ }^{511}$ It is generally accepted that intact verbal semantic memory, together with gravely impaired episodic/event memory is characteristic of the amnesic syndrome. ${ }^{12-14}$ Evidence of the converse, namely the relatively normal operation of episodic/ event memory in a patient with a semantic memory deficit, would strengthen the notion that these are two separate systems each with its own properties and characteristics and at the very least bolster the validity of the distinction. 


\section{Case history}

EM (born 1914) was a right-handed school-teacher who was investigated at the National Hospital in 1972 for progressive memory difficulties. A mild degree of cortical atrophy was demonstrated and the discharge diagnosis was that of atrophy of unknown origin. It was shown that her vocabulary comprehension was markedly impoverished (somewhat more so for abstract than concrete words), whereas her auditory perception, articulation and linguistic skills, in particular her use of syntax, were intact or nearly so. There was little evidence of impaired general intellectual functions. The present investigations were all undertaken in October/November 1972 and May/June 1973 and her performance on a variety of tasks attempted on both occasions is summarised in table 1. (Further details of the performance of normal

Table 1 EM-Baseline

\begin{tabular}{llll}
\hline & $\begin{array}{l}\text { November } \\
1972\end{array}$ & $\begin{array}{l}\text { May } \\
1973\end{array}$ & Degree of change \\
\hline $\begin{array}{l}\text { Raven's Progressive } \\
\text { Matrices } \\
\text { Sets B and C }\end{array}$ & $22 / 24$ & $21 / 24$ & Not significant \\
$\begin{array}{l}\text { WAIS Vocabulary } \\
\text { subtest } \\
\text { Age-scaled score }\end{array}$ & 7 & 6 & Not significant \\
$\begin{array}{l}\text { WAIS Digit Span } \\
\text { Age-scaled score }\end{array}$ & 11 & 16 & Improved \\
$\begin{array}{l}\text { Peabody Picture } \\
\text { Vocabulary Test }\end{array}$ & $42 / 60$ & $32 / 60$ & Mild deterioration \\
Items 42-101 & & & \\
$\begin{array}{l}\text { Modified Token } \\
\text { Test }\end{array}$ & $15 / 15$ & $12 / 15$ & Slight deterioration \\
\hline
\end{tabular}

controls and of patients with unilateral cerebral lesions on these tests are given by Coughlan and Warrington. ${ }^{4}$ ) Thus during this period there was some further deterioration of her language skills (for example in the Peabody Picture Vocabulary test), but her general intellectual level remained stable (for example in the Raven's Progressive Matrices) and her conversational speech remained fluent and wide ranging. Subsequently she continued to deteriorate and by 1975 she was so incapacitated that further testing became impracticable. (For a further account of her other cognitive skills see Warrington. ${ }^{5}$ )

\section{Experimental investigation}

\section{Stability of verbal comprehension}

EM attempted to define a pool of 121 spoken words41 nouns, 38 verbs and 42 adjectives, each class comprising approximately $50 \%$ high frequency and $50 \%$ low-frequency words (A and AA, and 1-49 occurrences per million respectively using the Thorndike-Lorge ${ }^{15}$ count). For the nouns it was considered that a wide concreteness range was sampled though no formal concreteness ratings were available for this pool of 121 words. It is quite certain that all 121 words would have been within her vocabularly premorbidly. She attempted to define this pool on two occasions separated by almost 7 months, the first being on 16 November 1972 and the second on 21 June 1973. The percentage of words correctly defined on each occasion, using a lenient scoring criterion (see below), is given in table 2. There

Table 2 EM-percentage of words correctly defined in each class

\begin{tabular}{llll}
\hline & $\begin{array}{l}\text { Nouns } \\
(N=41)\end{array}$ & $\begin{array}{l}\text { Verbs } \\
(N=38)\end{array}$ & $\begin{array}{l}\text { Adjectives } \\
(N=42)\end{array}$ \\
\hline 1st test occasion & 59 & 55 & 67 \\
2nd test occasion & 41 & 58 & 57 \\
\hline
\end{tabular}

were no significant differences in her levels of comprehension of the three classes of word. The consistency of her words definition responses on the two occasions is given in table 3 . In spite of her overall level of per-

Table 3 EM-consistency of word definitions over a seven month period

\begin{tabular}{llll}
\hline & & \multicolumn{2}{l}{ 2nd test occasion } \\
\cline { 3 - 4 } & & Correct & Incorrect \\
\hline 1st test occasion & Correct & 58 & 15 \\
& Incorrect & 2 & 46 \\
\hline
\end{tabular}

(Total pool $=121$ words)

formance showing slight deterioration during this period, there was a highly significant degree of response consistency (contingency coefficient 0.58 , maximum $=0.71$; $\left.\chi^{2}=62 \cdot 5, \mathrm{p}<0.001\right)$. It is striking that only two of the 48 words which could not be defined on the first occasion were judged to be satisfactorily defined on the second occasion. It appears that once a word had dropped from her vocabulary it was a permanent loss. On each occasion EM was required to classify each word by its grammatical class. Of the words of which she did not know the meaning she classified correctly 38/48 (chance $16 \pm 3 \cdot 3$ ) on the first occasion and $48 / 61$ (chance $20 \cdot 3 \pm 3 \cdot 7$ ) on the second occasion. (Only once, on the first occasion, did she misclassify a word she had defined satisfactorily.) It appears that she has retained the superordinate information as to the class of word even though the more precise connotations were lost.

\section{Error analysis}

EM's responses to the pool of 121 words described above were classified by three judges as follows:

(1) Correct-responses in which a reasonable knowledge of the word meaning was demonstrated using a fairly lenient criterion (for example a leaflet-"a bit of paper"). (2) Omissions responses in which EM appeared to have no comprehension of the word (for example melon-“I've forgotten").

(3) Vague responses in which EM appeared to have some very imprecise residual comprehension of the word but which were not sufficiently close to have been accepted as correct for the consistency analysis (for example 
Table 4 EM-error analysis of word definitions

\begin{tabular}{|c|c|c|c|c|c|}
\hline & \multirow{2}{*}{$\begin{array}{l}\text { Percentage of words } \\
\text { defined correctly }\end{array}$} & \multicolumn{4}{|c|}{ Percentage of each type of error in total number of errors } \\
\hline & & Omission & Vague & Phonological & Unclassifiable \\
\hline $\begin{array}{l}\text { November } 1972 \\
N=121\end{array}$ & 60 & 37 & 17 & 23 & 23 \\
\hline $\begin{array}{l}\text { June } 1973 \\
\mathrm{~N}=121\end{array}$ & 52 & 50 & 14 & 19 & 17 \\
\hline
\end{tabular}

Table 5 EM-performance on memory tests

\begin{tabular}{|c|c|c|c|c|}
\hline \multirow[t]{2}{*}{ Test 1} & \multirow{2}{*}{$\begin{array}{l}\text { Mean no words } \\
\text { recalled }\end{array}$} & \multirow[t]{2}{*}{ Test 2} & \multicolumn{2}{|l|}{ Recall score } \\
\hline & & & $H C$ & $L C$ \\
\hline EM & $2 \cdot 6$ & EM & 21 & 9 \\
\hline Controls (mean \& SD) & $3 \cdot 3 \pm 0.7^{*}$ & Left hemisphere & & \\
\hline Amnesics (mean \& SD) & $1 \cdot 1 \doteqdot 0.6^{*}$ & Lesions (mean \& SD) & $21 \cdot 5 \pm 10 \cdot 5 \dagger$ & $16.9 \div 8.6 \dagger$ \\
\hline
\end{tabular}

*from Baddeley and Warrington. ${ }^{17}$

tfrom Coughlan. ${ }^{18}$

merchant-"some sort of person, don't know what"). (4) Phonological responses in which EM appeared to be defining a target word phonemically similar to the stimulus word (for example erupt-“don't erupt me when I'm in bed asleep", presumably an attempt to define interrupt; eliminate-"shows, looks, lets you see", presumably an attempt to define illuminate). For an error response to be classified as phonological, half of the phonemes in the stimulus word had to occur in the erroneous target word.

(5) Unclassifiable responses which appeared to be unrelated to the stimulus word and not classifiable in any of the preceding categories (for example devote"when you change").

The distribution of errors made by EM in defining these words on both occasions is given in table 4. (The analysis is based on the consensus of the three judges' ratings, the eventual category to which a response was assigned being that in which at least two of the judges had placed it. In the case of disagreement between all three judges the response was placed in the Unclassifiable category.) The incidence of vague responses provides further evidence of partial comprehension of spoken words, a phenomenom previously reported by Warrington. ${ }^{5}$ The distribution of phonological errors did not appear to be related to word class (nouns 19\%; verbs $27 \%$; adjectives $17 \%$; - -averaged across both occasions) nor did the incorrect target word appear to be more or less concrete than the stimulus word (for example peasant_- "the peasant is a bird", presumably an attempt to define pheasant; exclaim-"you should exclaim things to me so I can understand", presumably an attempt to define explain). However, had a larger pool of phonological errors been available such effects might have become apparent.

Free recall of word lists

Test 1 EM attempted a free recall task (on 10 November. 1972) adapted from the procedure devised by Baddeley and Warrington ${ }^{17}$ to investigate patients with an organic amnesic syndrome. Fifteen lists of 10 nouns (sampling a wide frequency and concreteness range) from the original experiment were used. For each list there was a single presentation at a 2-second rate (a 3-second rate was used in the original experiment) and recall was required after a 35-second filled interval (a 30-second filled interval was used in the original experiment). In spite of these rather more rigorous testing conditions EM obtained a mean recall score of 2.6 words per list. A comparison of EM's performance and that of normal control and amnesic subjects from the original experiment is shown in table 5 . The normal control subjects (mean age 53.8) obtained a mean recall score of 3.3 words per list and two of these control subjects obtained identical scores to EM, namely 2.6. Furthermore, EM's mean recall score per list was superior to that of any of the amnesic subjects tested.

Test 2 EM attempted the free recall task (on 27 October 1972) described by Coughlan. ${ }^{18}$ The materials comprised four sets of three 10-word lists, each set reflecting a different category of word. These categories were high frequency (AA and $\mathrm{A}$ )-high concreteness (c > 4.7), high frequency-low concreteness $(c<4 \cdot 7)$, low frequency (1-49 occurrences per million)--high concreteness and low frequency-low concreteness.' Each list was read out three times at a 2 -second rate and recall was tested after a 35-second filled interval. EM scored 21/60 on the high concreteness word lists (summing across frequency levels) and $9 / 60$ on the low concreteness word 
lists (summing across frequency levels). A comparison of EM's performance and that of a group of subjects with left hemisphere lesions is shown in table 5. Compared with the patients with left hemisphere lesions her score on high concreteness words is close to the mean, even though the patients with left hemisphere lesions scored at a much higher overall level than EM on tests of word comprehension (see Coughlan ${ }^{18}$ ).

\section{Discussion}

In this study of a single case, EM, we report evidence relevant to two main issues-first, the taxonomy of semantic deficits and, second, the inter-relationship of verbal semantic memory and episodic/event memory for verbal material. We have found that EM's verbal vocabulary was stable albeit severely impoverished, that phonological errors occurred, and that her verbal recall skills were well preserved notwithstanding the constraints imposed by her relatively impaired word comprehension.

Warrington and Shallice ${ }^{7}$ have argued that a measure of response consistency provides one possible method of differentiating between a deficit which is essentially one of inaccessability and a deficit in which there is degradation of the representation of semantic information. They have argued that if an item can be accessed on some occasions and not others, the central representation of the semantic information is likely to be intact but inaccessible. Similarly if there is a repeated failure to access a particular item this would at least be consistent with the notion that there has been degradation of the semantic representation. Both these types of semantic deficit have now been described in the context of acquired dyslexia, namely the dyslexia characterised by an inconsistent written vocabulary (for example, CAV described by Warrington; ${ }^{19}$ AR described by Warrington and Shallice ${ }^{7}$ ) and the dyslexia characterised by an impoverished but stable written word vocabulary (for example, KF described by Shallice and Warrington). ${ }^{6}$ The former cases were interpreted as having a semantic access deficit and may be contrasted with $\mathrm{KF}$, for whom we presume that semantic representation was degraded. Following this line of argument we would suggest that the consistency within EM's impoverished vocabulary indicates that she does not have a semantic access deficit but rather that she has a category selective degradation of the central representation of verbal semantic information. (A patient with an access deficit within the domain of auditory verbal semantic memory has now been observed by one of us, EKW and will be reported.)

The question arises as to whether EM's phonological errors are analogous with the visual error categories which are frequently noted in acquired dyslexia and, if so, what is their locus in the verbal comprehension system. A visual error in reading is identified when at least half of the letters of the stimulus word occur in the error response (for example, charm-"chair", uncle-“unique"). Similarly, here a phonological error is identified when at least half the phonemes of the stimulus word in the erroneous target word (for example, peasant-. "the peasant is a bird"; in this case pheasant is assumed to be the erroneous target word). We would argue that such an error is an auditory analogue of the visual error in reading.

It is accepted that visual errors are not a trivial or uninteresting consequence of faulty visual or perceptual processing. This we would argue is also the case of EM's phonological errors; her pure tone and speech audiograms were normal, performance on an auditory word discrimination test was normal and she made no errors on a word repetition task. There has been some debate as to the origin of visual erros-Patterson ${ }^{20}$ has implicated a deficit of the visual logogen (a pre-semantic categorical stage of processing) whereas Shallice and Warrington ${ }^{6} 9$ have favoured a locus within the verbal semantic system and a similar position has been adopted by Morton and Patterson, ${ }^{8}$ and Coltheart. ${ }^{21}$ There is no reason to suppose that EM's ability to perceive spoken words (or in Morton's terminology, to achieve an auditory imput logogen analogous to the visual input $\operatorname{logogen} 822$ ) was impaired. Indeed, the earlier finding that her auditory span for words she did not comprehend was no worse than for words she did comprehend and superior to her span for nonsense syllables was interpreted as strong evidence that pre-semantic categorical word perception was intact. ${ }^{5}$ Therefore it seems unlikely that her phonological errors are arising at this stage and consequently a semantic locus is a plausible candidate.

Following Shallice and Warrington's ${ }^{9}$ formulation of the origin of visual errors, we suggest that the outputs from an auditory word perception system can activate the semantic representations of more than one word. We would assume that the normal differential loading of the input to the semantic system in favour of the actual stimulus item would tend to be vitiated or negated if its semantic representation were degraded or inaccessible, and consequently the probability of accessing the erroneous target would be increased. Thus the semantic unit corresponding to a phonologically similar, but semantically dissimilar word, could be sufficiently activated to produce a phonological error response.

We have interpreted EM's verbal comprehension impairment in terms of a stable verbal semantic 
memory deficit and the relationship between this deficit and her episodic/event memory deserves consideration. Although weak, her performance on a task of recalling lists of concrete words was relatively satisfactory, her level being close to the mean ability of a consecutive series of patients with left hemisphere lesions, who were able to function at a higher level on tests of semantic knowledge. On the Baddeley and Warrington ${ }^{17}$ free recall task her performance was in the normal range and superior to any of the amnesic subjects tested. Thus although the impairment of verbal semantic memory clearly could constrain the efficiency of verbal retention it would appear that under certain conditions retention can reach a normal level.

The selective impairment of episodic/event memory, semantic memory being intact, as is observed in the amnesic syndrome, is not by itself incompatible with a unitary theory of memory-it could be argued that the contents of semantic memory have very high trace strengths as a result of rehearsal and usage, and are therefore more robust than newly learned information. However the converse which we have observed in EM, the relative preservation of episodic/event memory skills despite markedly impaired verbal semantic memory, present serious difficulty for such a theory. This double dissociation between deficits of verbal semantic memory and episodic/event memory suggests that these skills are subserved by different neural substrates.

We are grateful to Dr RTC Pratt for permission to investigate EM and to report our findings.

\section{References}

${ }^{1}$ Schuell H, Jenkins JJ. Reduction of vocabulary in aphasia. Brain 1961 ;84:243-61.

${ }^{2}$ Goodglass H, Klein B, Carey P, Jones KJ. Specific semantic word categories in aphasia. Cortex 1966; 2:74-89.

${ }^{3}$ Goodglass H, Baker E. Semantic field, naming and auditory comprehension in aphasia. Brain Lang 1976;3:359-74.

4 Coughlan AK, Warrington EK. Word-comprehension and word-retrieval in patients with localised cerebral lesions. Brain 1978;101:163-85.

${ }^{5}$ Warrington EK. The selective impairment of semantic memory. Q J Exp Psychol 1975;27:635-57.
${ }^{6}$ Shallice T, Warrington EK. Word recognition in a phonemic dyslexic patient. $Q J$ Exp Psychol 1975; 27:187-99.

7 Warrington EK, Shallice T. Semantic access dyslexia. Brain 1979;102:43-63.

${ }^{8}$ Morton J, Patterson KE. A new attempt at an interpretation, or an attempt at a new interpretation. In: Coltheart M, Patterson KE, Marshall JC, eds. Deep Dyslexia. London: Routledge and Kegan Paul, 1980.

${ }^{9}$ Shallice T, Warrington, EK. Single and multiple component central dyslexic syndromes. In: Coltheart M, Patterson KE, Marshall JC, eds. Deep Dyslexia. London: Routledge and Kegan Paul, 1980.

${ }^{10}$ Tulving E. Episodic and semantic memory. In: Tulving E, Donaldson W, eds. Organization of memory. New York: Academic Press, 1972.

${ }^{11}$ Kinsbourne M, Wood F. Short-term memory process and the amnesic syndrome. In: Deutsch D, Deutsch JA, eds. Short-term memory. New York: Academic Press, 1975.

12 Talland GA. Deranged Memory. New York: Academic Press, 1965.

13 Milner B, Corkins S, Teuber HL. Further analysis of hippocampal amnesic syndrome: 14 year follow-up study of HM. Neuropsychologia 1968;6:215-34.

14 Baddeley AD, Warrington EK. Memory coding and amnesia. Neuropsychologia 1973;11:159-65.

15 Thorndike EL, Lorge I. The Teacher's Word Book of 30,000 Words. New York: Teachers College, 1944.

${ }^{16}$ Brown WP, Ure DMN. Five rated characteristics of 650 word association stimuli. Br J Psychol 1969;60: 223-50.

17 Baddeley AD, Warrington EK. Amnesia and the distinction between long and short term memory. J Verb Learning Verb Behaviour 1970;9:176-89.

${ }^{18}$ Coughlan AK. Effects of localised cerebral lesions and dysphasia on verbal memory. $J$ Neurol Neurosurg Psychiatry 1979;42:914-23.

19 Warrington EK. Concrete word dyslexia. Br J Psychol $1981 ; 72: 175-96$.

${ }^{20}$ Patterson KE. Phonemic dyslexia: errors of meaning and the meaning of errors. $Q J$ Exp Psychol 1978; 30:587-608.

${ }^{21}$ Coltheart M. Deep dyslexia; a right hemisphere hypothesis. In: Coltheart $M$, Patterson KE, Marshall JC, eds. Deep Dyslexia. London: Routledge and Kegan Paul, 1980.

${ }^{22}$ Morton J. Facilitation in word recognition: experiments causing change in the logogen model. In: Kolers PA, Wrolstad ME, Bouma H, eds. Proc conference on the processing of visible language. New York: Plenum Publishing Co, 1979. 